\title{
Predicting and verifying the intended and unintended consequences of large-scale ocean iron fertilization
}

\author{
John J. Cullen ${ }^{1, *}$, Philip W. Boyd ${ }^{2}$ \\ ${ }^{1}$ Department of Oceanography, Dalhousie University, 1355 Oxford Street, Halifax, Nova Scotia B3H 4J1, Canada \\ ${ }^{2}$ NIWA Centre for Chemical and Physical Oceanography, Department of Chemistry, University of Otago, PO Box 56, \\ Dunedin, New Zealand
}

\begin{abstract}
Ocean iron fertilization (OIF) is being considered as a strategy for mitigating rising atmospheric $\mathrm{CO}_{2}$ concentrations. One model for implementation is the sale of carbon offsets. Modeling studies predict that OIF has the potential to produce a material difference in the rise of atmospheric $\mathrm{CO}_{2}$ over the next several decades, but this could only be attained by alteration of the ecosystems and biogeochemical cycles of much of the world's oceans. The efficacy of OIF on this scale has not been proven. However, the consequences of successful implementation must be considered now, for 2 important reasons: (1) to determine if the environmental effects would be predictable and verifiable, and if so, acceptable; and (2) to establish whether the basis for valuing carbon offsets - an accurate audit of net reductions in cumulative greenhouse gas potential over $100 \mathrm{yr}$ - can be met. Potential side-effects of widespread OIF that must be considered include a reduced supply of macronutrients to surface waters downstream of fertilized regions, increased emissions of the potent greenhouse gases nitrous oxide and methane, and changes in the extent or frequency of coastal hypoxia. Given the uncertainties inherent in ocean models, predictions of environmental effects must be backed up by measurements. Thus, to go forward with confidence that the effects of rising $\mathrm{CO}_{2}$ could indeed be mitigated through OIF over the next century, and to establish the foundations for auditing carbon offsets, it must be explicitly demonstrated that methods exist to predict and detect downstream effects of OIF against the background of both climate variability and global warming. We propose that until the side-effects of widespread OIF can be shown to be verifiable - and there is good reason to believe that they cannot-OIF should not be considered a viable technology for climate mitigation.
\end{abstract}

KEY WORDS: Ocean fertilization - Climate change · Climate change mitigation · Carbon offsets · Ecological effects $\cdot$ Hypoxia $\cdot$ Nitrous oxide

Resale or republication not permitted without written consent of the publisher

\section{INTRODUCTION}

The relentless rise of atmospheric $\mathrm{CO}_{2}$ concentrations presents us with one of the greatest challenges of our times. It has been established that fossil-fuel emissions must be drastically reduced to stabilize atmospheric $\mathrm{CO}_{2}$ soon enough to avoid rapid climate change with very serious consequences for humanity (IPCC 2007). It is also clear that a broad range of strategies for capturing and sequestering $\mathrm{CO}_{2}$ must be pursued. Direct manipulation of the radiative balance of Earth, for example through stratospheric sulfur injections (Crutzen 2006), is also being considered. The latter, and other proposals that involve large-scale manipulations of the planet, are sometimes termed 'geoengineering'; they merit special scrutiny because they would impose pervasive changes to earth systems with inherently uncertain consequences (Kintisch 2007). Here, we examine one geoengineering proposal: fertilization of the ocean on a scale large enough to make a significant difference to the rise of atmospheric $\mathrm{CO}_{2}$ over the next several decades. 


\section{PROPOSED STRATEGY FOR MITIGATING CLIMATE CHANGE}

Despite profound uncertainties about its ultimate consequences, widespread fertilization of the ocean is being seriously considered as a strategy for mitigating climate change (Buesseler et al. 2008). One reason for contemplating this potentially risky manipulation of marine ecosystems on an unprecedented scale is that the consequences of taking no action could be worse. The same reasoning is used to justify consideration of a broad range of geoengineering proposals (Kintisch 2007). The premise of these arguments is that the geoengineering activity could slow the rise of atmospheric $\mathrm{CO}_{2}$ concentrations or otherwise modify global warming enough to significantly mitigate greenhouse-gas driven climate change. Pacala \& Socolow (2004) describe a portfolio of technologies they claim could solve the carbon and climate problem for the next half century. Each of seven 'stabilization wedges' would rise over $50 \mathrm{yr}$ to account for $1 \mathrm{Gt} \mathrm{C} \mathrm{yr}^{-1}$ of sequestered atmospheric $\mathrm{CO}_{2}$ or reduced $\mathrm{CO}_{2}$ emissions - corresponding to $0.47 \mathrm{ppm}$ of atmospheric $\mathrm{CO}_{2} \mathrm{yr}^{-1}$ (Lassey et al. 1996). Such wedges would stabilize net $\mathrm{CO}_{2}$ emissions for long enough to permit a plateau at $500 \mathrm{ppm}$ to be achieved by substantially reduced fossil fuel emissions in subsequent years. These technologies are identified as having 'the potential to produce a material difference by 2054' (Pacala \& Socolow 1968, p. 968). Consistent with the time scale of this scenario, technologies for sequestering atmospheric $\mathrm{CO}_{2}$ should do so for at least $100 \mathrm{yr}$ - the standard for permanence of carbon sequestration strategies (Powell 2008).

In principle, ocean iron fertilization (OIF) could represent a stabilization wedge; modeling studies predict that sustained fertilization (for decades) of so-called high-nutrient, low-chlorophyll (HNLC) regions of the ocean (i.e. up to $30 \%$ of the World Ocean) would

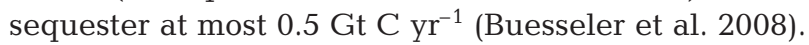
Fertilization of some oligotrophic waters (which in total account for nearly $50 \%$ of ocean area) with iron or a mix of iron and macronutrients (i.e. via induced upwelling) could lead to more sequestration of carbon in the ocean by enhancing the growth of phytoplankton and/or stimulating nitrogen fixation, with subsequent sinking of organic material to the deep sea (Karl \& Letelier 2008, this Theme Section). Thus, although it is by no means proven, the potential exists for OIF to make a significant difference to atmospheric $\mathrm{CO}_{2}$ concentrations (e.g. carbon sequestration of about 0.5 Gt C $\mathrm{yr}^{-1}$ ), but this could only be attained by intentional alteration of the ecosystems and biogeochemical cycles of much of the world's oceans for a century or more.

It has been argued that implementation of an OIF strategy would depend on there being 'acceptable and predictable environmental impacts' (Buesseler et al. 2008). We agree and add that, as with essentially all predictions of complex earth processes involving the biosphere, projections of the consequences of OIF are inherently uncertain. What, then, is the standard for predictability? Reasonably, predictions would have to be sufficiently accurate to exclude the possibility of unacceptable environmental impacts. In turn, they would have to be validated by comparison with appropriate environmental observations. Since the model of OIF as a climate mitigation strategy is widespread implementation, sustained for decades and leading to carbon sequestration for at least $100 \mathrm{yr}$, the requirement for prediction and verification of environmental impacts must be applied not only to individual applications or pilot programs, but also to global alteration of the ocean for a century or more. To do less would be to embark on this course of global environmental manipulation, trusting - without adequate foundation - that unacceptable consequences could be detected in time to halt this activity. We feel that it is necessary to rely on more than trust.

\section{OIF AND CARBON OFFSETS}

OIF is controversial not only because of its uncertain effects, but also because commercial interests are pursuing a market-driven strategy for implementation: multiple nutrient applications (e.g. roughly $200 \times$ $200 \mathrm{~km}$ ) for carbon offsets sustained for decades. The feasibility of this strategy has been pointedly questioned (Zeebe \& Archer 2005), and issues such as the effect of frequency of OIF (sporadic versus continuous) on carbon sequestration (Arrigo \& Tagliabue 2005) appear to have been ignored. However, if OIF could reach its potential for carbon sequestration and cause a material difference in atmospheric $\mathrm{CO}_{2}$ (a major justification for considering such action despite uncertainties that may never be resolved), the resulting carbon offsets would be worth many billions of euros and if the process were as simple as some proponents have suggested, revenues would greatly exceed costs. This raises many concerns, including the worry that the cumulative, large-scale effects of many market-driven implementations would lead to a classic 'tragedy of the commons' (Hardin 1968, Chisholm et al. 2001). The response of proponents is a clear acknowledgement that OIF should be subject to international oversight, with requirements for careful validation of carbon sequestration and other environmental side-effects

It follows that, whether the objective is to evaluate OIF comprehensively as a strategy for mitigating climate change or more specifically as a technology for generating carbon offsets (i.e. through a series of com- 
mercially funded nutrient applications ultimately leading to large-scale changes in the ocean), the effects of OIF must be shown to be acceptably predictable and verifiable, locally and globally. Here, we describe intended and unintended effects of OIF that must be predicted and discuss the accuracy that would be required to verify these predictions effectively enough to exclude the possibility of materially significant counteracting or negative environmental effects.

\section{INTENDED AND UNINTENDED EFFECTS OF OIF}

The central objective of OIF is alteration of the structure and function of pelagic ecosystems and the associated biogeochemical cycles. This is not meant to imply that today's ocean is pristine; we know that climate variability influences ocean ecosystems in many ways and that anthropogenic activities are already affecting climate (IPCC 2007). Also, humans have polluted coastal systems (GESAMP 2001) and fundamentally altered marine food webs by fishing down top predators and depleting fish stocks world-wide (Jackson et al. 2001, Myers \& Worm 2003). Regardless, OIF merits very careful evaluation because using it broadly enough to mitigate climate change would ultimately result in the manipulation of ocean ecosystems on basin scales.

Simply, OIF is intended to promote nutrient utilization in surface layers of the ocean to produce organic matter that will sink and decompose in the deep sea, isolated from the atmosphere. Iron would be added to HNLC areas of the ocean, where the availability of this trace element limits the accumulation of phytoplankton and thus the utilization of macronutrients. Local effects of individual applications are well recognized and have been studied over weeks at relatively small scales (i.e. $10 \times 10 \mathrm{~km}$ ) of experimental ocean fertilization (Boyd et al. 2007b). Addition of iron to oligotrophic (low-nutrient, low-chlorophyll [LNLC]) waters would be intended to stimulate nitrogen fixation supported by utilization of residual phosphate (and possibly, added nutrients), ultimately resulting in the export of organic material from the surface layer (Karl \& Letelier 2008). To date, the efficacy of LNLC fertilization has not been demonstrated; open ocean enrichment experiments with iron have had a minor impact on nitrogen fixation (Rees et al. 2006, unpubl. data), and global models (e.g. Tagliabue et al. 2008) suggest a relatively small effect of aerosol iron supply on LNLC regions. But questions of scale and modes of implementation remain unexplored (Karl \& Letelier 2008) and there are unknowns surrounding what environmental factors stimulate nitrogen fixers (Deutsch et al. 2007, Hutchins et al. 2007). If LNLC fertilization does sequester car- bon, we must know if the consequences would be predictable, verifiable and acceptable. It is thus appropriate at this time to conduct the heuristic exercise of exploring the potential effects of successful, widespread ocean fertilization.

\section{Direct effects of individual applications}

If effective, each application of iron to the ocean would have several direct results that are described and discussed elsewhere in this Theme Section (see Law 2008, Watson et al. 2008): (1) Phytoplankton would bloom, leading to depletion of macronutrients in the surface layer. (2) After varying degrees of repackaging through food web processes and the formation of aggregates (marine snow), a proportion of the organic matter produced by the bloom would sink from the surface layer, roughly the upper $100 \mathrm{~m}$. (3) Below the surface layer, the downward flux of organic matter would decrease with depth, approximating a power law function (Buesseler et al. 2007), due primarily to decomposition by microbes - consuming oxygen and regenerating nutrients and $\mathrm{CO}_{2}$ in the process-and the grazing of particles by zooplankton. (4) Consequently, only a portion of the organic matter that sank out of the surface layer would reach deep waters that are likely to stay out of contact with the atmosphere for $100 \mathrm{yr}$ or more, i.e., beyond the ' 100 yr horizon'. This is the carbon that would be considered to be sequestered. (5) Some fertilizations could stimulate blooms of communities that produce dimethylsulfide (DMS), the principal natural source of sulfur to the atmosphere, which influences climate by its role in cloud formation and modifying radiative properties of the earth (Andreae 1990). Enhanced DMS emissions could potentially reinforce the climate-mitigation effects of OIF by increasing the earth's albedo (Law 2008). Except perhaps for enhanced production of DMS, these general predictions should apply to LNLC (Karl \& Letelier 2008), as well as HNLC waters.

It is seldom recognized explicitly, but has nonetheless been observed, that at the end of an effective fertilization, surface waters would be depleted of nutrients (Boyd et al. 2004) and plankton biomass would be low because a proportion of the organic matter produced by fertilization would have sunk to deeper layers.

\section{Direct effects of sustained and widespread OIF}

As assumed in models used to predict the efficacy of OIF in a climate mitigation scenario (e.g. Aumont \& Bopp 2006, Tagliabue et al. 2008), sustained and widespread fertilization would lead to replacement of iron 
limitation with iron sufficiency in broad expanses of the ocean. The previously unused macronutrients in the surface layer would have been stripped from the water by phytoplankton and delivered to depth along with carbon-as sinking particulate organic matter. Given the stoichiometry of synthesis and regeneration of organic material in the sea, several biogeochemical and ecological consequences would be expected from this iron-induced pumping of organic particles to depth across broad expanses of ocean: (1) Lower concentrations of macronutrients in the surface layer, likely leading to the limitation of new production by the vertical flux of nitrate, or if nitrogen fixation is stimulated, phosphate. The engineered ironsufficient, macronutrient-limited pelagic ecosystems would thus be structured in a fundamentally different way from their present state, in which upper limits to the growth of phytoplankton are hypothesized to depend on supplies of iron from atmospheric deposition as well as from below (Jickells et al. 2005). The new state is intended to mimic what is thought to have occurred naturally during glacial periods (Martin 1990). (2) Higher concentrations of carbon at depth, associated with the organic material that sank from the surface layer. Most of this would be dissolved inorganic carbon (DIC) associated with decomposition of that organic matter, and much of the DIC would accumulate below the surface layer but above the $100 \mathrm{yr}$ horizon, i.e. in waters that would come in contact with the atmosphere in less than 100 yr. (3) Lower concentrations of oxygen below the surface layer, corresponding directly to the extra DIC produced by decomposition. (4) Higher concentrations of macronutrients at depth, roughly in stoichiometric proportion to the OIFinduced excess DIC and deficiency in oxygen.

It is important to remember that the products of OIF that do not reach the $100 \mathrm{yr}$ horizon - likely the majority of that which sinks below $100 \mathrm{~m}$ - still affect the chemistry and biology of subsurface waters by increasing nutrients and DIC and decreasing oxygen. A comprehensive audit of the effects of OIF would have to include careful assessment of these changes in middepth waters.

\section{Downstream effects of sustained and widespread OIF}

Expected results of OIF have qualitatively (and in sufficiently detailed models, quantitatively) predictable ecological and biogeochemical consequences that can be referred to as downstream effects: (1) OIF would reduce the surface nutrient inventory, and thus the productivity of plankton communities, in large expanses of ocean downstream of the fertilizations. This might severely diminish their ability to support fisheries (Gnanadesikan et al. 2003, Gnanadesikan \& Marinov 2008, this Theme Section). (2) As recognized early on by Fuhrman \& Capone (1991), increased particle flux from widespread OIF would promote oxygen depletion and the regeneration of nutrients and $\mathrm{CO}_{2}$ in subsurface waters, which could lead generally to increased production and efflux of greenhouse gases such as $\mathrm{N}_{2} \mathrm{O}$ and methane (with 300x and $23 \times$ the global warming potential of $\mathrm{CO}_{2}$, respectively, calculated by molecular weight). (3) Fertilization-induced oxygen depletion and regeneration of nutrients at middepths could alter source waters for some coastal upwelling systems. Effects of similar alterations are illustrated by examples from the coast of Oregon influenced by anomalous high-nutrient, low-oxygen upwelled source water in 2002 (Grantham et al. 2004) and very low $\mathrm{O}_{2}$ water in 2006 (Chan et al. 2008); effects included nearshore hypoxia with fish kills and transients of increased emissions of $\mathrm{CO}_{2}$ and $\mathrm{N}_{2} \mathrm{O}$ from the ocean associated with upwelling (Lueker 2004). Through its incremental influence on mid-depth oxygen and nutrients, OIF-induced alteration of source waters for coastal upwelling should increase the frequency or extent of coastal hypoxia, but by what amount, we do not know. As the events of 2002 and 2006 illustrate, incompletely understood natural processes will always be a factor. If dramatic anoxia like that observed in 2006 (Chan et al. 2008) occurred several years after OIF had even slightly altered source waters, there would likely be an active discussion of the extent to which those who applied fertilizer might be liable. (4) Higher nutrients in source waters for coastal upwelling can have positive effects, especially if the system is not driven to hypoxia; enhanced delivery of nutrients to upwelling systems influenced by OIF-enriched source waters should lead to increased productivity in the surface layer and export of production from it, although supplies of $\mathrm{N}$ would likely be reduced by the conversion of ammonium and nitrate to $\mathrm{N}_{2}$ by denitrification and anammox in suboxic waters (Arrigo 2005). (5) For enrichment of oligotrophic waters to stimulate $\mathrm{N}$-fixation, alteration of subsurface $\mathrm{N}: \mathrm{P}$ nutrient ratios is expected-and indeed will be exploited (Karl \& Letelier 2008). This could have important, and at present unknown, influences on the structure of the pelagic food web (Arrigo 2005).

A common feature of these downstream effects is that they would be expected to build up gradually over time in response to the cumulative influence of repeated fertilizations, ultimately altering much of the ocean. As we discuss below, capabilities exist to model the effects and to make measurements relevant to validation of model predictions, but quantifying perturbations directly attributable to OIF on a global scale during coming decades of changing climate presents a 
huge challenge (Denman 2008, this Theme Section, Watson et al. 2008). Indeed, modeling studies indicate the difficulties that exist in discerning the signal of global climate change over that of climate variability during the coming decades (Boyd et al. 2007a); assessing the influence of OIF will require detecting its direct and indirect effects over the 2 sources of climaterelated variability - with confidence.

\section{CRITERIA FOR EFFECTIVE VERIFICATION}

Now that we have identified the expected (but not necessarily easily quantifiable) influences of widescale OIF, we can return to the conclusion that it is premature to sell carbon offsets for OIF unless it can be demonstrated to have 'acceptable and predictable environmental impacts' (Buesseler et al. 2008). It is useful to start with a list of what should be predicted.

- Reduced vertical export of carbon from waters immediately downstream, due to depletion of surface water nutrients, should be assessed and deducted from the vertical carbon flux associated directly with each fertilization. To do so, we would need to quantify the extent to which nutrients were depleted and the effect of that depletion on vertical carbon fluxes that would have occurred had the patch of water been left alone. Knowledge of the mean state and variability envelope (around the mean) of the nutrient fields prior to OIF is a prerequisite for this quantification (see Watson et al. 2008). The use of autonomous sensor systems on floats and gliders (Riser \& Johnson 2008) would assist with large-scale quantification of changes in nutrients and dissolved oxygen.

- Changes in the emissions of $\mathrm{N}_{2} \mathrm{O}$ to the atmosphere during the $100 \mathrm{yr}$ after fertilization would have to be predicted and any net increases - multiplied by a global warming potential of 300 times that of $\mathrm{CO}_{2}-$ would have to be deducted from the estimate of net carbon sequestration. Given that waters below the surface layer but above the 100 yr horizon will be enriched with nitrogen and somewhat depleted in oxygen, increased emissions to the atmosphere are expected (Gnanadesikan et al. 2003). Thus, $\mathrm{N}_{2} \mathrm{O}$ production would have to be assessed for these middepth waters, along with atmospheric exchange (Nevison et al. 2004). To estimate the required limit of detection, consider that the global warming benefit associated with ocean carbon sequestration of

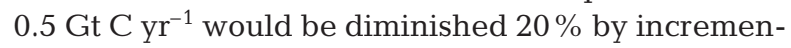
tal emission of $0.8 \mathrm{Tg} \mathrm{N}$ as $\mathrm{N}_{2} \mathrm{O} \mathrm{yr}^{-1}$. This difference is coincidentally about $20 \%$ of the estimated ocean production of $\mathrm{N}_{2} \mathrm{O}$ (Nevison et al. 2004) and well within the uncertainty of the estimate. For further discussion, see Law (2008).
- Alterations to methane emissions from the global ocean should also be assessed. However, simple calculations indicate that even large changes in methane production may not be a problem in this context; emissions of methane would have to increase by $16 \mathrm{Tg} \mathrm{CH}_{4} \mathrm{Yr}^{-1}$ to

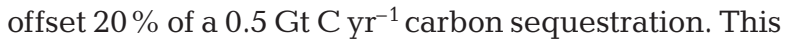
is well over $10 \times$ the estimated marine source of methane to the atmosphere (Kock et al. 2008), so, unless other relevant facts arise, increases in methane production might safely be considered an acceptable consequence of OIF.

Other expected effects of OIF cannot be quantified in terms of $\mathrm{CO}_{2}$ greenhouse gas equivalents, but would have economic and societal impacts that should be assessed to evaluate net benefits of ocean fertilization. - In some regions of the ocean, purposefully nutrientdepleted surface waters would be subducted, then upwelled into the thermocline hundreds or thousands of $\mathrm{km}$ away. These upwelled waters would have lower concentrations of nutrients, limiting their potential to support productive ecosystems (Carr \& Kearns 2003). It will be important to estimate not only the reduction of carbon sequestration, but also the impacts on food webs and on the yields of fisheries in particular. Using calculations they recognized to be uncertain, Gnanadesikan et al. (2003) related regional fisheries landings to export production (transport of organic carbon to depth) and estimated that 1 US ton of reduced export flux corresponded to \$US5 of fisheries value. Applying this estimate to results of one of their $100 \mathrm{yr}$ simulations of OIF, Gnanadesikan et al. (2003) calculated that the long-term cost to fisheries of the southeast Pacific region associated with sequestering 1 US ton $\mathrm{C}$ through fertilization of the tropical ocean would be \$US150 US ton $^{-1} \mathrm{C}$ sequestered. If history is any guide, regardless of uncertainties in the cost estimate, we should expect major repercussions if fisheries yields decline in regions predicted to be starved of nutrients due to upstream OIF. Attributing causality to a major change in fisheries is notably difficult, and the compounding effects of climate variability and global warming promise to make determinations even harder to make.

- As discussed above, alteration of subsurface waters has its own consequences. Widespread OIF above waters that impinge on coastal regions should lead to increased extent, and possibly frequency, of hypoxia in coastal ecosystems supplied by artificially enriched mid-depth waters, but we have little basis on which to predict the degree of increase. Major hypoxic events have significant ecological and economic impact, so it will be important to determine how much influence OIF might have. Comprehensive ocean surveys with autonomous sensor systems (nitrate and oxygen) informing detailed ocean models should help. It will nonetheless be very difficult to 
determine the degree to which OIF may have contributed to coastal hypoxia during coming decades of climate variability and major anthropogenic inputs of nutrients to coastal waters (GESAMP 2001).

We conclude that predicting the effects of OIF will be a formidable challenge and validating the predictions will be very difficult. These obstacles to effective auditing of OIF impacts are compounded by the possibility of unpredictable effects.

\section{UNPREDICTABLE EFFECTS}

The preceding discussion has been based on the heuristic assumption - by no means proven - that OIF would be broadly effective at stimulating the growth of phytoplankton and utilization of surface nutrients, leading to globally significant sequestration of carbon. We have done this because it is imprudent to embark on a course of action that could influence the whole world without considering the consequences of complete implementation with expected results. In turn, we should consider the consequences of unexpected results.

It has been argued that we cannot predict the ecological and biogeochemical responses to OIF (Chisholm et al. 2001). This argument is supported by a range of unanticipated outcomes of OIF experiments to date. Specifically, markedly different algal community composition of blooms were reported from the Subarctic Pacific Iron Experiment for Ecosystem Dynamics Study (SEEDS) I and II experiments at the same site in the northwest Pacific (Boyd et al. 2007b). A large-scale phosphate fertilization in the phosphorus-poor eastern Mediterranean resulted, surprisingly, in a decrease in phytoplankton stocks. After careful analysis, this result was attributed to other food web components out-competing phytoplankton for the added phosphate (Thingstad et al. 2005). The result was entirely unexpected and appreciated only in retrospect; it illustrates that when complex marine ecosystems are manipulated, the most obvious prediction, e.g. a phytoplankton bloom in response to P-fertilization or a bloom of fastsettling diatoms sequestering carbon in response to iron fertilization, cannot be guaranteed.

Larger-scale changes of ecosystems must also be considered. There is now considerable evidence that environmental forcing, associated with climate variability and/or climate change, results in unexpected changes in ecosystems - so-called 'regime shifts' that can alter phytoplankton community structure and also indirectly impact on higher trophic levels (see Boyd \& Doney 2003, their Table 7.1). One example of such a shift is the sudden appearance of extensive coccolithophore blooms in the Bering Sea, with subsequent large-scale changes of regional biogeochemistry and food web structure (Stockwell et al. 2001). OIF for climate mitigation will alter regions of similar scale and it may not be possible to assess unwanted effects until after they happen.

\section{UNCERTAINTY, ACCOUNTABILITY AND THE SCALE OF OIF}

We agree with Buesseler et al. (2008) that uncertainties surrounding OIF are too great to justify the selling of carbon offsets for ocean fertilization at this time and we add that some uncertainties will never be fully resolved. But when it comes to the recognized threat of climate change, arguments can be made for going forward in the face of uncertainty. That is, acceptance of risk - and perhaps a relaxation of the standards for carbon offset valuation - might be tolerated if OIF showed great promise for mitigating climate change and thereby reducing the recognized risks of increasing atmospheric $\mathrm{CO}_{2}$. However, this justification for accepting uncertainty and associated risks diminishes greatly when proposals for OIF are scaled back to much more modest levels that, on their own, would not make a substantial difference to climate (for example, as recently presented by one company, Climos, on their site, http:// www.climos.com/faq.html\#solve_global_warming, accessed April 28, 2008). It follows that as the ultimate objectives of OIF are scaled back, the tolerance of uncertainty and the assessment of benefits as compared to risks should be adjusted accordingly. At the same time it should be recognized that there is no guarantee that one company's restraint will be mimicked by others in a carbon-offset market. Further, no proposals have been made to define the conditions under which restrictions on cumulative fertilization should be imposed. We therefore feel that assessment of OIF as a climate mitigation strategy should consider the effects of widespread fertilization as discussed above.

\section{CONCLUSIONS}

We conclude that if OIF is pursued as a climate mitigation strategy, it will affect much of the ocean over $100 \mathrm{yr}$ or more. So its effects should be predicted on the scale of the global ocean and verified against the background of climate variability and climate change over coming decades. This is also required for comprehensive auditing of carbon offsets. We propose that until the capability for predicting and detecting downstream side-effects of OIF can be demonstrated - and there is good reason to believe that it cannot-OIF should not be considered a viable technology for climate mitigation. 


\section{LITERATURE CITED}

Andreae MO (1990) Ocean-atmosphere interactions in the global biogeochemical sulfur cycle. Mar Chem 30:1-29

Arrigo KR (2005) Marine microorganisms and global nutrient cycles. Nature 437:349-355

> Arrigo KR, Tagliabue A (2005) Iron in the Ross Sea. II. Impact of discrete iron addition strategies. J Geophys Res 110: C03010

Aumont O, Bopp L (2006) Globalizing results from ocean in situ iron fertilization studies. Global Biogeochem Cycles 20:GB2017

Boyd PW, Doney SC (2003) The impact of climate change and feedback processes on the ocean carbon cycle. In: Fasham MJR (ed) Ocean biogeochemistry - the role of the ocean carbon cycle in global change. Springer, Berlin, p 157-193

Boyd PW, Law CS, Wong CS, Nojiri Y and others (2004) The decline and fate of an iron-induced subarctic phytoplankton bloom. Nature 428:549-553

Boyd PW, Doney SC, Strzepek R, Dusenberry J, Lindsay K, Fung I (2007a) Climate-mediated changes to mixed-layer properties in the Southern Ocean: assessing the phytoplankton response. Biogeosciences Discuss 4:4283-4322

Boyd PW, Jickells T, Law CS, Blain S and others (2007b) Mesoscale iron enrichment experiments 1993-2005: synthesis and future directions. Science 315:612-617

Buesseler KO, Lamborg $\mathrm{CH}$, Boyd PW, Lam PJ and others (2007) Revisiting carbon flux through the ocean's twilight zone. Science 316:567-570

Buesseler KO, Doney SC, Karl DM, Boyd PW and others (2008) Ocean iron fertilization - moving forward in a sea of uncertainty. Science 319:162

Carr ME, Kearns EJ (2003) Production regimes in four Eastern Boundary Current systems. Deep-Sea Res II 50:3199-3221

Chan F, Barth JA, Lubchenco J, Kirincich A, Weeks H, Peterson WT, Menge BA (2008) Emergence of anoxia in the California Current large marine ecosystem. Science 319:920

Chisholm SW, Falkowski PG, Cullen JJ (2001) Dis-crediting ocean fertilization. Science 294:309-310

Crutzen PJ (2006) Albedo enhancement by stratospheric sulfur injections: A contribution to resolve a policy dilemma? Clim Change 77:211-220

$>$ Denman KL (2008) Climate change, ocean processes and ocean iron fertilization. Mar Ecol Prog Ser 364:219-225

> Deutsch C, Sarmiento JL, Sigman DM, Gruber N, Dunne JP (2007) Spatial coupling of nitrogen inputs and losses in the ocean. Nature 445:163-167

Fuhrman JA, Capone DG (1991) Possible biogeochemical consequences of ocean fertilization. Limnol Oceanogr 36: 1951-1959

GESAMP (United Nations Joint Group of Experts on the Scientific Aspects of Marine Environmental Protection) (2001) A sea of troubles GESAMP Rep Stud 70

> Gnanadesikan A, Marinov (2008) Export is not enough: nutrient cycling and carbon sequestration. Mar Ecol Prog Ser 364:289-294

> Gnanadesikan A, Sarmiento JL, Slater RD (2003) Effects of patchy ocean fertilization on atmospheric carbon dioxide and biological production. Global Biogeochem Cycles 17: 1050

> Grantham BA, Chan F, Nielsen KJ, Fox DS and others (2004) Upwelling-driven nearshore hypoxia signals ecosystem and oceanographic changes in the northeast Pacific. Nature 429:749-754

Hardin G (1968) The tragedy of the commons. Science 162: $1243-1248$

Hutchins DA, Fu FX, Zhang Y, Warner ME and others (2007)
$\mathrm{CO}_{2}$ control of Trichodesmium $\mathrm{N}_{2}$ fixation, photosynthesis, growth rates, and elemental ratios: implications for past, present and future ocean biogeochemistry. Limnol Oceanogr 52:1293-1304

IPCC (Intergovernmental Panel on Climate Change) (2007) Summary for policymakers. Contribution of Working Groups I, II and III to the Fourth Assessment Report of the Intergovernmental Panel on Climate Change. IPCC, Geneva

Jackson JBC, Kirby MX, Berger WH, Bjorndal KA and others (2001) Historical overfishing and the recent collapse of coastal ecosystems. Science 293:629-637

Jickells TD, An ZS, Andersen KK, Baker AR and others (2005) Global iron connections between desert dust, ocean biogeochemistry, and climate. Science 308:67-71

Karl DM, Letelier RM (2008) Nitrogen fixation-enhanced carbon sequestration in low nitrate, low chlorophyll seascapes. Mar Ecol Prog Ser 364:257-268

Kintisch E (2007) Should we study geoengineering? A Science panel discussion. Science 318:1054-1055

Kock A, Gebhardt S, Bange HW (2008) Methane emissions from the upwelling area off Mauritania (NW Africa). Biogeosciences Discuss 5:297-315

Lassey KR, Enting IG, Trudinger CM (1996) The earth's radiocarbon budget. A consistent model of the global carbon and radiocarbon cycles. Tellus 48B:487-501

> Law CS (2008) Predicting and monitoring the effects of largescale ocean iron fertilization on marine trace gas emissions. Mar Ecol Prog Ser 364:283-288

Lueker TJ (2004) Coastal upwelling fluxes of $\mathrm{O}_{2}, \mathrm{~N}_{2} \mathrm{O}$, and $\mathrm{CO}_{2}$ assessed from continuous atmospheric observations at Trinidad, California. Biogeosciences 1:101-111

Martin JH (1990) Glacial-interglacial $\mathrm{CO}_{2}$ change: the iron hypothesis. Paleoceanography 5:1-13

Myers RA, Worm B (2003) Rapid worldwide depletion of predatory fish communities. Nature 423:280-283

> Nevison CD, Lueker TJ, Weiss RF (2004) Quantifying the nitrous oxide source from coastal upwelling. Global Biogeochem Cycles 18:GB1018

Pacala S, Socolow R (2004) Stabilization wedges: solving the climate problem for the next 50 years with current technologies. Science 305:968-972

Powell H (2008) Dumping iron and trading carbon: Profits, pollution, and politics all will play roles in ocean iron fertilization. Oceanus 46:22-25

Rees AP, Law CS, Woodward EMS (2006) High rates of nitrogen fixation during an in situ phosphate release experiment in the Eastern Mediterranean Sea. Geophys Res Lett 33:L10607

Riser SC, Johnson KS (2008) Net production of oxygen in the subtropical ocean. Nature 451:323-325

Stockwell DA, Whitledge TE, Zeeman SI, Coyle KO and others (2001) Anomalous conditions in the south-eastern Bering Sea, 1997: nutrients, phytoplankton and zooplankton. Fish Oceanogr 10:99-116

Tagliabue A, Bopp L, Aumont O (2008) Ocean biogeochemistry exhibits contrasting responses to a large scale reduction in dust deposition. Biogeocsciences 5:11-24

Thingstad TF, Krom MD, Mantoura RFC, Flaten GAF and others (2005) Nature of phosphorus limitation in the ultraoligotrophic eastern Mediterranean. Science 309:1068-1071

Watson AJ, Boyd PW, Turner SM, Jickells TD, Liss PS (2008) Designing the next generation of ocean iron fertilization experiments. Mar Ecol Prog Ser 364:303-309

Zeebe RE, Archer D (2005) Feasibility of ocean fertilization and its impact on future atmospheric $\mathrm{CO}_{2}$ levels. Geophys Res Lett 32:L09703 